\title{
Paraneoplastic neurologic syndrome
}

INSERM

\section{Source}

INSERM. (1999). Orphanet: an online rare disease and orphan drug data base.

Paraneoplastic neurologic syndrome. ORPHA:36388

Paraneoplastic neurological syndromes (PNS) can be defined as remote effects of cancer that are not caused by the tumor and its metastasis, or by infection, ischemia or metabolic disruptions. 